\title{
Improved model for the thermal performance calculation of non-planar window frames for building simulation programs
}

\section{Maureen de Gastines, Ayelén Villalba \& Andrea Pattini}

To cite this article: Maureen de Gastines, Ayelén Villalba \& Andrea Pattini (2016): Improved model for the thermal performance calculation of non-planar window frames for building simulation programs, Journal of Building Performance Simulation

To link to this article: http://dx.doi.org/10.1080/19401493.2016.1177117

\section{Published online: 02 May 2016.}

Submit your article to this journal

a

View related articles $\sqsubset$

View Crossmark data $\nearrow$ 


\title{
Improved model for the thermal performance calculation of non-planar window frames for building simulation programs
}

\author{
Maureen de Gastines*, Ayelén Villalba and Andrea Pattini \\ Laboratorio de Ambiente Humano y Vivienda - Instituto Ciencias Humanas Sociales y Ambientales (LAHV INCIHUSA), Consejo \\ Nacional de Investigaciones Cientificas y Técnicas (CONICET), Avenida Ruiz Leal S/N Pque Gral San Martín, C.P. 5500 Mendoza, \\ Argentina
}

(Received 25 September 2015; accepted 20 March 2016)

\begin{abstract}
Windows are a key factor for designing energy-efficient buildings, particularly the frame area that can produce high thermal bridging. This paper deals with accurately estimating heat transfer through window frames under fluctuating film coefficients. The one-dimensional frame conductance model traditionally used by building simulation programs is analysed and an alternative model is proposed, which takes into account the non-planar morphology of studied frames. This model shows a positive agreement with the results obtained from a two-dimensional heat-transfer simulation program, demonstrating that the thermal performance of high-conductance non-planar frames strongly depends on the ratio between the boundary surface area and the projected frame area. According to the results, the traditional conductance model seems to be suitable for all frames with a thermal transmittance lower than $5 \mathrm{~W} / \mathrm{m}^{2} \mathrm{~K}$; however, frames with a U-factor higher than $6.2 \mathrm{~W} / \mathrm{m}^{2} \mathrm{~K}$ need an alternative conductance model that better reflects the $2 \mathrm{D}$ nature of frame sections.
\end{abstract}

Keywords: thermal conductance; window frame; film coefficient; frame compactness; simulation; U-factor

\section{Introduction}

Buildings account for a third of all of the energy consumption in the world. The International Energy Agency (International Energy Agency 2013) expresses an urgency for changing our current energy and climate path, also pointing out that the development of energy-efficient building envelopes is a key factor for reducing greenhouse gas emissions from HVAC. In particular, they describe single-pane windows with clear-glass and poorly insulated frames as very inefficient, also mentioning that these types of windows are still being installed in many regions around the world. Windows are a key factor in the energy efficiency of buildings, not only because they provide natural light and solar gain, but also because they generally have a higher thermal transmittance than other components of the building envelope. This means that a large amount of heat transfer occurs through windows. In particular, the window frame typically occupies between $20 \%$ and $30 \%$ of the window area (Gustavsen 2008) and when the frame U-factor is higher than the centre-ofglass U-factor, it can significantly bring the performance of the window down. Therefore, when assessing existing or new buildings for energy-saving potential, it is important to accurately address the complex heat transfer mechanisms through windows and especially through their frames. Building energy simulation programs should thus incorporate adequate window heat transfer models and algorithms.

A number of studies have been carried out on the modelling approaches for windows within simulation programs. Booten, Kruis, and Christensen (2012) compared the different ways of modelling heat transfer that occurs through windows for two commonly used simulation programs, EnergyPlus and DOE-2. They encountered significant differences in the calculated heating loads related to windows, which are up to $41 \%$ for single-glazed windows, and proposed a number of changes in order to address the various issues identified in the source code of the programs related to the calculation of indoor and outdoor convection coefficients. Lyons, Wong, and Bhandari (2010) and Lam, Ge, and Fazio (2014) compared the results obtained by using the different glazing modelling alternatives available in EnergyPlus and discussed the strengths and limitations of each approach. Other investigations (Lomas et al. 1997; Manz et al. 2006; Loutzenhiser et al. 2007a, 2007b) have contrasted simulation results with measured data in order to validate software models for windows. Nowadays, most building simulation programs allow for a layer-by-layer description of glazing. Heat balance is calculated at each time step in order to determine glazing surface temperatures and calculate the heat transfer that comes through the glazing.

\footnotetext{
*Corresponding author. Email: mdegastines@mendoza-conicet.gob.ar
} 
Loutzenhiser et al. (2009) urge that assessing the overall impact of a window requires an adequate consideration of edge effects and window frame. For edge effects, the authors describe how to input thermal bridges due to glazing spacers and installation (interface between window and external wall) in several types of building simulation software. In EnergyPlus, for example, it is possible to input the ratio of edge-of-glass conductance to centre-of-glass conductance (Uiuc 2009). Passive House is the only standard that incorporates the thermal performance of the window installation, via an installation $\Psi$-value. Otherwise, the thermal bridge of the glass/frame interface is generally included as a characteristic of the frame, while the installation thermal bridge has to be taken into account in the same way as the other thermal bridges of the building, that is, by calculating modified thermophysical properties or by adding additional constructions to represent the edge losses (Strachan et al. 2015).

As far as window frames are concerned, because of their complex geometry, two-dimensional heat transfer simulations and/or experimental analyses are needed to accurately characterize thermal behaviour of the frames. Most building energy simulation programs simplify the thermal conduction problem by considering a onedimensional heat flow through the envelope, and cannot appropriately address the complexity of heat flow through frames. Therefore, they generally use the frame U-factor as an input for the characterization of heat transfer through window frames.

U-factor calculation can be done through the finite element method using specific software such as THERM or BISCO. In this work, THERM 6.3 is used because it is a free software which is frequently being updated by its developers - Lawrence Berkeley National Laboratory (LBNL). This software can model the complicated geometries of building products, such as frames, in order to evaluate their energy efficiency and local temperature patterns. THERM 6.3 is also the currently approved software for NFRC (National Fenestration Rating Council of United States) simulations. A number of investigations (e.g. Griffith et al. 1998) have analysed the adjustment of THERM simulations to experimental measurements and have contributed to algorithm improvements, achieving a good accuracy $(10 \%$ according to Gustavsen et al. (2008)). One of the main advantages of THERM is that its results can be used with WINDOW (another LBNL software) in order to determine total window product U-factors and Solar Heat Gain Coefficients. The main limitation of THERM is that it does not have a user-friendly interface, which restrains its use among designers and architects.

The available thermal transmittance data are generally the certified U-factor, but this value can be determined by different standards for any given window. A comparative study of the North American and European fenestration energy performance standards was carried out based on $\mathrm{U}$-factor calculation for a variety of windows with different frame and glazing typologies (RDH Building Engineering 2014), demonstrating that the frame U-factor calculated according to NFRC conditions could be up to $5 \%$ lower and 24\% higher than the ones obtained under ISO 10077 conditions. This result can be explained by the different calculation procedures and boundary conditions used in the standards. The authors concluded that additional research work should be undertaken to study the relationship between certified U-factors and optimal window selection for a particular climate.

As an example of the strong dependence of U-factors on environmental conditions, it was observed that the difference between NFRC U-factor and particular climate conditions U-factor for a given window could even be bigger than the difference between the U-factors of a thermally broken and unbroken aluminium window under the same conditions (De Gastines, Villalba, and Pattini 2014). Therefore, it is crucial that building energy simulation software take into account U-factor variations resulting from the fluctuations of environmental conditions during the simulation run period in order to get representative and accurate results that are consistent with the specific design and technology of the specific window.

In many types of building simulation software, the use of frame conductance values attempts to solve the problem of U-factor dependence on environmental conditions. The underlying concept is that the overall frame resistance (reciprocal of frame U-factor) can be calculated from the sum of the frame resistance (reciprocal of frame conductance), the outside air resistance $(1 / \mathrm{hco})$ and the inside air resistance $(1 / \mathrm{hci})$. Frame conductance is an important input for building energy simulation programs which have at least one dynamic surface heat transfer correlation (Loutzenhiser et al. 2009). However, this conductance method is suitable for homogeneous and flat envelope constructions where the heat flow can be considered one dimensional, like window glazing. Thus, the validity of this approach is arguable for frames that include multiple internal cavities. Aluminium frames are especially inhomogeneous, since internal cavities have much lower effective conductivity values than aluminium. It is also questionable for non-planar fenestration systems where heat flow is two dimensional as well.

U-factor dependence on environmental conditions is particularly significant in the case of aluminium frames without a thermal break. Indeed, according to ASHRAE (2009), frame heat loss in most fenestration is controlled by a single component or controlling resistance. For aluminium frames without a thermal break, most of the resistance to heat flow is provided by the inside film coefficient, whereas for thermally broken aluminium, the controlling resistance is the depth of the thermal break material in the heat flow direction, and for vinyl- or woodframed fenestration, it is the shortest distance between the inside and the outside surfaces. Since thermal behaviour depends mainly on environmental conditions for thermally 
unbroken aluminium frames, concerns are raised about the traditional conductance calculation method, which are particularly important for the analysis of those frames.

Despite the significant progress made in recent decades in developing highly insulating frames (Byars and Arasteh 1992; Gustavsen 2008), aluminium frames without thermal break still hold a significant proportion of windows worldwide. In the case of the Argentinean market, this technological backwardness can be explained by the lack of energy efficiency standards for buildings and windows as well as a certified institute for creating and maintaining these standards. Another factor may be governmental energy subsidies which do not encourage the market development towards energy savings. Since these windows still exist in many buildings, and considering that they produce high thermal bridging, the description and understanding of this type of heat transfer are crucial in order to perform improved and more accurate building simulations that can estimate real energy savings which would result from improvements in windows technology.

Although aluminium windows without thermal break are extensively used, there is no precise information about typical thermal transmittance values for those frames. The ASHRAE Fundamental Handbook (2009) specifies reference values for frame $\mathrm{U}$-factors depending on the frame material, operability and the number of glass panes, but those values were determined using NFRC 100-91 and have not yet been updated to the current rating methodology NFRC 100-2004. The latter differs from the older version because it includes detailed radiation models, which, according to Griffith et al. (1998), improve the accuracy of simulated U-factors for projecting windows, especially for lower performance products. Therefore, the reliability of the provided data is uncertain. Apart from this, the Argentinean norm IRAM 11507-4 (2001) indicates a single value of $6.02 \mathrm{~W} / \mathrm{m}^{2} \mathrm{~K}$ for the thermal transmittance of aluminium frames without thermal break, regardless of typology or glazing width. This reference value is questionable too, because the conditions in which the value was calculated have not been specified, and it is much lower than the values published by ASHRAE $\left(13.51 \mathrm{~W} / \mathrm{m}^{2} \mathrm{~K}\right.$ for a single-glazed, operable aluminium window frame).

This work aims to develop a model that can properly describe the variations of highly conductive and non-planar frame U-factors according to environmental conditions for use in building simulation software in order to improve the precision of the estimates of heat transfer through a key element of the building envelope.

\section{Methodology}

\subsection{Selection of case studies}

Case studies were selected among the windows available in the Argentinean market. This is relevant since the most commonly used windows in Argentina are single-pane, aluminium, thermally unbroken, highly non-planar horizontal slider windows. Information was gathered about all relevant windows available in the local market. Then, a morphological study was performed, grouping the identified frames into a number of categories according to their similarities in terms of shape and dimensions. Next, one frame was selected to represent each category.

\subsection{Frame and edge-of-glass $U$-factors calculation for the selected windows}

A detailed calculation of the U-factors for the selected windows was performed using the WINDOW 6.3 and THERM 6.3 software, in accordance with the methods described in THERM 6.3/WINDOW 6.3 NFRC Simulation Manual (Robin et al. 2011) based on the norm ISO 15099 (ISO 2003b) and NFRC 100-2004 procedures (National Fenestration Rating Council 2004). Regarding the properties of the different materials, default conductivity values were used for the felt and EPDM weatherstrips. However, a new material was defined for aluminium parts, with a thermal conductivity of $199 \mathrm{~W} / \mathrm{m}^{2} \mathrm{~K}$ (considering that the frame profiles are elaborated with aluminium alloy 6063$\mathrm{T} 6$, which belongs to the $\mathrm{AlMgSi}$ alloys and has a thermal conductivity of between 197 and $201 \mathrm{~W} / \mathrm{m}^{2} \mathrm{~K}$ ). The emissivity was set to 0.2 , taking into account that an emissivity of 0.9 should be assigned later at the external (painted) surfaces of the frame.

According to the NFRC methodology, the frame Ufactor is calculated with the glass in place; thus, the obtained value includes part of the edge effects at the interface between the frame and glass. The rest of them are taken into account through the use of an edge-of-glass thermal transmittance, $U_{\mathrm{e}}$, which characterizes the heat transfer through the $63.5-\mathrm{mm}$-wide edge-of-glass area. Both values $\left(U_{\mathrm{f}}\right.$ and $\left.U_{\mathrm{e}}\right)$ are direct outputs from THERM simulations. The edge region between the frame and the glazing generally produces significant thermal bridging because of the spacer bar (Gustavsen, Uvsløkk, and Jelle 2005; Elmahdy 2006). Since only single-pane windows (i.e. without spacer) are considered in this study, edge effects at the frame/glass interface should be reduced. However, since reference norms (ISO 2003a, 2003b; National Fenestration Rating Council 2004) mention the calculation of this thermal bridge, edge-of-glass U-factor is calculated for the different case studies in order to verify the low impact of edge effects on the total U-factor.

These norms, however, do not consider installation thermal bridge as part of heat transfer. Moreover, Berggren and Wall (2013) showed that the relative effect of thermal bridges increases when more insulation is used. Therefore, since the studied frames are highly conductive, it can be assumed that installation thermal bridge has a low relative effect on the thermal behaviour of the envelope. Also, as mentioned in Section 1, installation thermal bridge can be taken into account by adding an increase in thermal 
transmittance to the homogeneous part of the envelope. For those reasons, installation thermal bridges were not studied in this work.

All the constitutive sections of each frame were simulated in THERM, and the frame and edge U-factors were calculated by area-weighting the thermal performance of the different sections of each frame. Then, the files were imported into WINDOW to calculate the complete window (1200 mm x $1500 \mathrm{~mm})$ U-factor and conductance value. Conductance values obtained for each case study were then analysed.

\subsection{Analysis of the traditional frame conductance model}

The traditional frame conductance model used to estimate heat transfer in different environmental conditions was tested according to the conductance values obtained in Section 2.2 for the frames studied. After identifying the weaknesses of that model, the development of an alternative model was undertaken, aiming to allow a more accurate estimate of frame U-factor variations depending on environmental conditions for the frames under study.

\subsection{Development of an alternative model $U_{\mathrm{f}}\left(\boldsymbol{h}_{\mathrm{i}}, \boldsymbol{h}_{\mathrm{o}}\right)$}

\subsubsection{Model $U_{S_{j}}\left(h_{\mathrm{i}} ; h_{\mathrm{o}}\right)$ for a frame section}

The development of an alternative model for the calculation of the thermal transmittance of frames as a function of film coefficients was carried out in successive stages. For simplification, at first, the study focused on a single section, the one having the greatest influence on the U-factor of the whole frame.

A new model $U_{S_{j}}\left(h_{\mathrm{i}}, h_{\mathrm{o}}\right)$ was proposed, which incorporates corrective coefficients depending on the specific morphology of each profile. To assess the model adjustment, the U-factor of the selected section was calculated both according to the model predictions and through simulation in THERM for six different couples of inside and outside combined film coefficients $\left(h_{\mathrm{i}}, h_{\mathrm{o}}\right)$. Temperature was set to $21^{\circ} \mathrm{C}$ inside and $-18^{\circ} \mathrm{C}$ outside as in previous simulations. Since a simplified convection/linearized radiation model was used at this stage, slightly ventilated cavities were defined in THERM on both sides of the window, as recommended by Section 6.7.1 of ISO 15099 (2003b). Then, the results obtained from the model and from simulations were compared using the root mean square error (RMSE).

\subsubsection{Model $U_{\mathrm{f}}\left(h_{\mathrm{i}} ; h_{\mathrm{o}}\right)$ for the whole frame}

The model $U_{S_{j}}\left(h_{\mathrm{i}} ; h_{\mathrm{o}}\right)$ for one section was extrapolated to the whole frame, expressing the corrective coefficients as a function of the morphological characteristics of every section which constitutes the frame. To assess the validity of this model $U_{\mathrm{f}}\left(h_{\mathrm{i}}, h_{\mathrm{o}}\right)$, the same method was employed as in Section 2.4.1. Considering that this verification requires up to 30 simulations for each frame, three samples were selected within the case studies. This selection was made according to the results of Section 2.2, by choosing the frames with the highest, lowest and closest to average Ufactors. RMSE was then calculated in order to evaluate the predictions for each model (Equations (1) and (3)).

\subsubsection{Application of the model to an aluminium thermally broken frame}

In order to determine whether the proposed model applies to other frame technologies, a thermally broken aluminium slider window frame was simulated in THERM under the same six inside and outside film coefficient combinations, and the RMSE was then calculated to quantify the agreement of the alternative model predictions with the simulation results. The result was then compared with the RMSE obtained for the traditional conductance equation.

\section{Results}

\subsection{Selection of case studies}

The profiles of horizontal slider windows developed by five Argentinean aluminium extrusion companies were analysed. Each company offers several product lines with different performance levels and designs. Although most product lines have several variants, making it possible to assemble different combinations of profiles, the base product of each line was selected (without accessories and with identical sill and head sections). In total, 37 frame models were collected.

Horizontal slider windows are composed of a frame and two (internal and external) sliding sashes. Figure 1 shows the different sections which form the fenestration assembly. The frame is composed of a sill, a head and two jamb profiles, while each sash comprises stiles and rails. The meeting rail section is formed by the union of stiles, considering that the window is closed.

The main criteria considered for grouping the frames into different categories were the general performance level (along with the manufacturer's guidelines), the shape and width of the sill profile, and the evenness between the various elements which form the whole frame. In all, $86 \%$ of the collected frame models were classified into eight categories and one representative sample was chosen for each category, reducing the number of simulation windows to eight. Table 1 indicates the characteristics that define each group and shows the vertical and horizontal sections of the eight samples selected as case studies.

Ratios of total to projected boundary surface area on the internal and external sides of the frames are tabulated in Table 2. All values are much greater than 1, which makes all studied frames highly non-planar.

\subsection{Calculation of the $U$-factor of the frames}

Since all samples have identical sill and head sections, only five sections need to be defined, referred to as S1-S5, as 


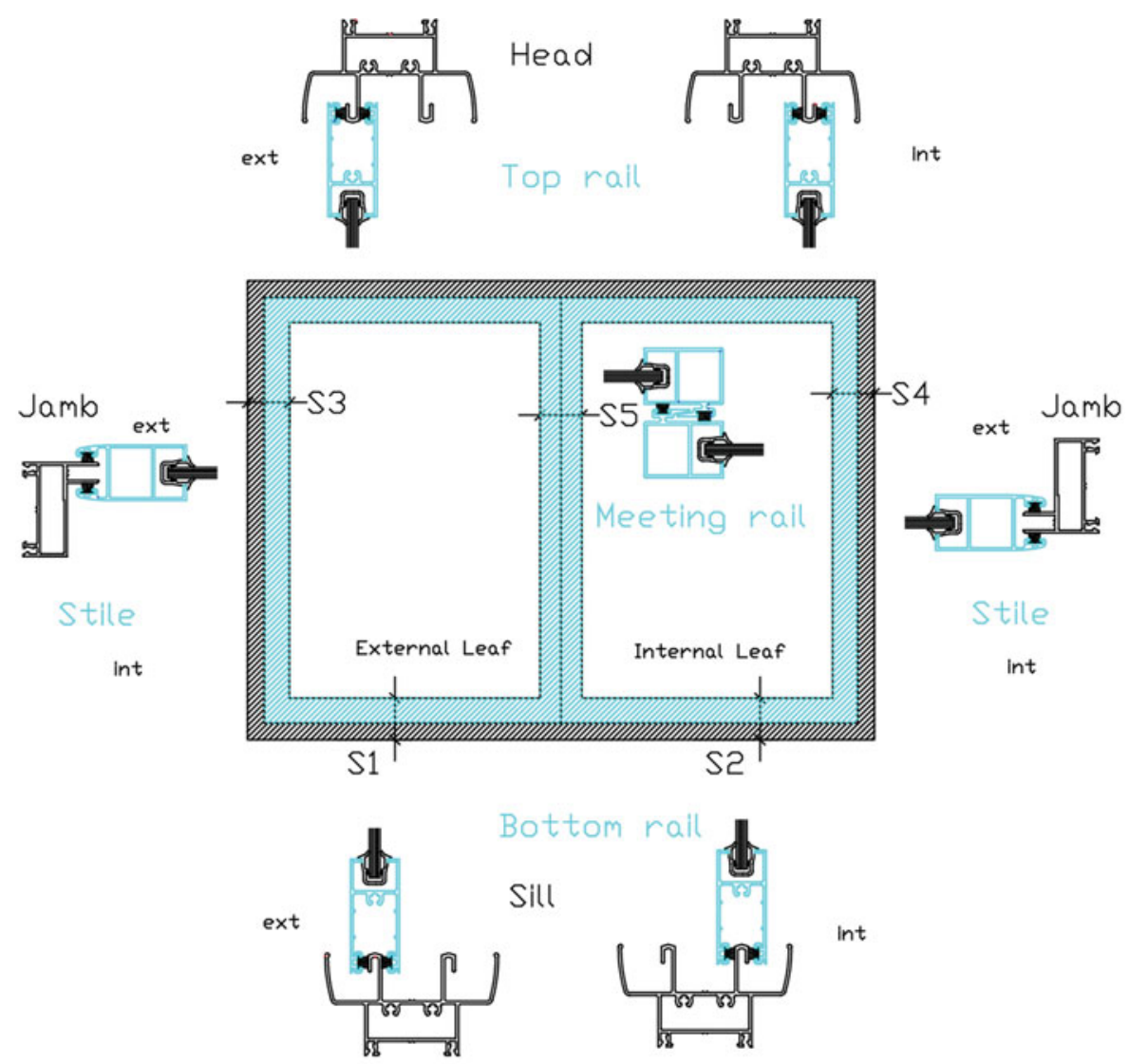

Figure 1. Window constitutive elements.

shown in Figure 1. The sill (and consequently the head) and the jambs of the window are divided into two sections according to the sash position (internal or external). Separately, frames 5 and 7 have identical sill and jamb sections, which means that they only have three different sections $(\mathrm{S} 1=\mathrm{S} 3$ and $\mathrm{S} 2=\mathrm{S} 4)$. In total, 36 simulations are thus needed to calculate the thermal transmittance of all case studies.

Although only single pane windows were considered in this investigation, the frames studied have different nominal thickness of the glazing, between 5 and $8 \mathrm{~mm}$. To estimate the deviation due to this difference, the U-factors of sections combined with a $5 \mathrm{~mm}$ wide glazing and then with an $8 \mathrm{~mm}$ wide glazing were compared. Variations of about $1 \%$ were found, which means that simulating each frame with its nominal glazing thickness will not significantly affect the validity of the results and comparison between them.

\subsubsection{U-factors of different frame sections}

Each section of the eight study cases was simulated in THERM, in accordance with the NFRC methodology. The U-factors obtained are indicated in Table 3 . The results are plotted in Figure 2 to compare the resulting values.
U-factors of the different sections range between 7.12 and $12.96 \mathrm{~W} / \mathrm{m}^{2} \mathrm{~K}$. Significant variability can be observed between the U-factors of the different sections, even among those that belong to the same frame. For example, there is an absolute difference of $4.01 \mathrm{~W} / \mathrm{m}^{2} \mathrm{~K}$ between the U-factors of sections S2 and S5 of frame 1. Conversely, frame 5 stands out for having thermal behaviour that is much more uniform (maximum absolute difference of $0.30 \mathrm{~W} / \mathrm{m}^{2} \mathrm{~K}$ between one section and another), which can be partially explained by the fact that it has identical sill/rail and jamb/stile profiles.

As can be observed in Figure 2, $U_{S_{1}}>U_{S_{2}}$ and $U_{S_{3}}>$ $U_{S_{4}}$ in all the case studies, which indicates that the sash position (internal or external) affects the thermal transmittance value of the profile. Also, frames 4, 6 and 8 stand out for having lower $U_{S_{3}}$ and $U_{S_{4}}$ values than $U_{S_{1}}$ and $U_{S_{2}}$ values. A particularity of those frames is that, unlike their sill profiles, their jamb profiles have lateral fins. Therefore, it can be assumed that lateral fins impinge on the frame U-factor.

\subsubsection{Frame and edge-of-glass U-factors calculation for the whole windows}

After obtaining the different U-factors for the different sections, the whole frame and edge-of-glass U-factors were 
Table 1. Descriptions of each category and illustrations of the selected samples (sill, jamb and meeting rail sections).
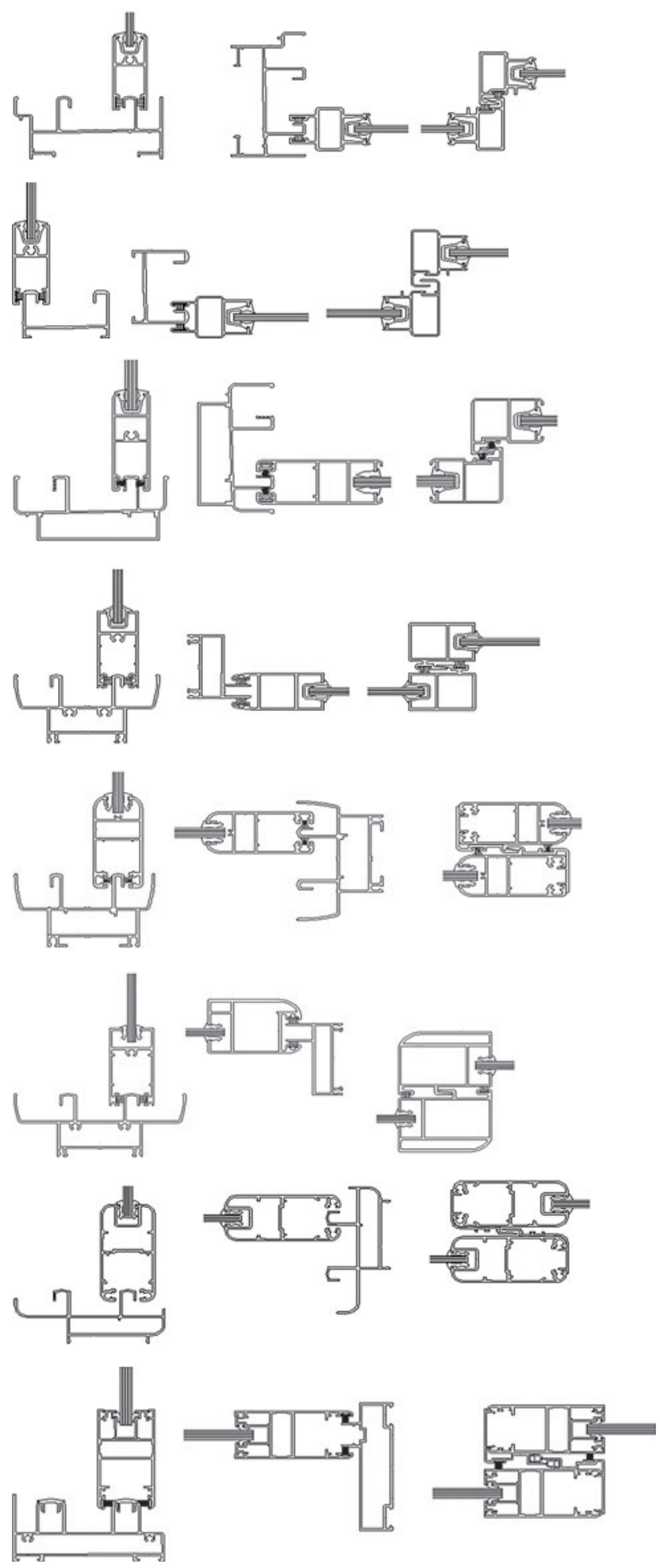

Category 1 (includes nine models)

- Performance level: economical

- Same sill and jamb profiles

- Different rail and stile profiles

- Bottom rail width: $19 \mathrm{~mm}$

Category 2 (includes three models)

- Performance level: economical

- Same sill and jamb profiles

- Different rail and stile profiles

- Bottom rail width: $19 \mathrm{~mm}$

- No lateral fins

Category 3 (includes three models)

- Performance level: medium

- Same sill and jamb profiles

- Different rail and stile profiles

- Bottom rail width: $19 \mathrm{~mm}$

Category 4 (includes four models)

- Performance level: medium

- Different sill and jamb profiles

- Different rail and stile profiles

- Bottom rail width: $23 \mathrm{~mm}$

Category 5 (includes five models)

- Performance level: medium

- Same sill and jamb profiles

- Same rail and stile profiles

- Bottom rail width: $28 \mathrm{~mm}$

Category 6 (includes three models)

- Performance level: high

- Different sill and jamb profiles

- Different rail and stile profiles

- Bottom rail width: $31 \mathrm{~mm}$

Category 7 (includes three models)

- Performance level: high

- Same sill and jamb profiles

- Same rail and stile profiles

- Bottom rail width: 34,40 or $42 \mathrm{~mm}$

Category 8 (includes two models)

- Performance level: high

- Different sill and jamb profiles

- Same rail and stile profiles

- Bottom rail width: $40 \mathrm{~mm}$ calculated by area-weighting those values. Table 4 shows the frame, edge-of-glass and centre-of-glass U-factors for the eight case studies (considering standard dimensions $1200 \mathrm{~mm} \times 1500 \mathrm{~mm}$ ). Frame 8 has the lowest U-factor $\left(8.79 \mathrm{~W} / \mathrm{m}^{2} \mathrm{~K}\right)$, followed by frame $2\left(8.81 \mathrm{~W} / \mathrm{m}^{2} \mathrm{~K}\right)$, whereas frames 1 and 6 have the highest U-factor $(10.62$ and $10.38 \mathrm{~W} / \mathrm{m}^{2} \mathrm{~K}$, respectively). The frame where the Ufactor most closely approximates the average value of 


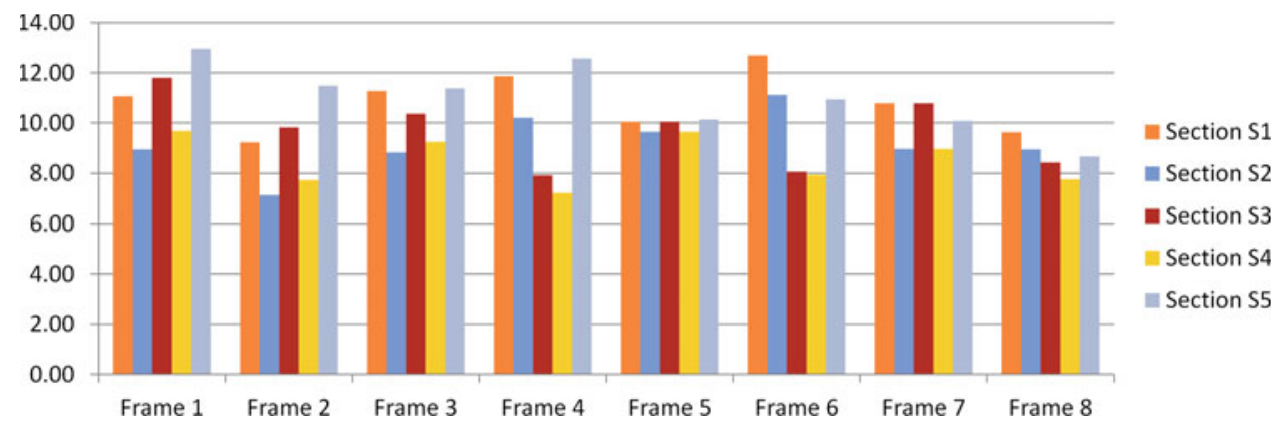

Figure 2. Comparison between the U-factors of each section for the eight samples.

Table 2. Ratios of frame total to projected boundary surface area on the internal and external sides.

\begin{tabular}{lcc}
\hline & \multicolumn{2}{c}{ Ratio of total to projected boundary surface area } \\
\cline { 2 - 3 } & Inside boundary & Outside boundary \\
\hline Frame 1 & 2.18 & 2.58 \\
Frame 2 & 2.12 & 2.12 \\
Frame 3 & 1.99 & 2.40 \\
Frame 4 & 2.04 & 2.04 \\
Frame 5 & 1.91 & 2.02 \\
Frame 6 & 2.28 & 2.28 \\
Frame 7 & 2.14 & 2.47 \\
Frame 8 & 1.78 & 1.69 \\
\hline
\end{tabular}

Table 3. U-factors (in $\mathrm{W} / \mathrm{m}^{2} \mathrm{~K}$ ) of each section of the eight samples (according to the NFRC methodology).

\begin{tabular}{lrrrrr}
\hline & $\begin{array}{c}\text { Section } \\
\text { S1 }\end{array}$ & $\begin{array}{r}\text { Section } \\
\text { S2 }\end{array}$ & $\begin{array}{r}\text { Section } \\
\text { S3 }\end{array}$ & $\begin{array}{c}\text { Section } \\
\text { S4 }\end{array}$ & $\begin{array}{c}\text { Section } \\
\text { S5 }\end{array}$ \\
\hline Frame 1 & 11.06 & 8.95 & 11.79 & 9.69 & 12.96 \\
Frame 2 & 9.22 & 7.12 & 9.82 & 7.73 & 11.49 \\
Frame 3 & 11.28 & 8.82 & 10.36 & 9.24 & 11.38 \\
Frame 4 & 11.87 & 10.20 & 7.91 & 7.21 & 12.56 \\
Frame 5 & 10.05 & 9.65 & 10.05 & 9.65 & 10.13 \\
Frame 6 & 12.69 & 11.11 & 8.06 & 7.94 & 10.94 \\
Frame 7 & 10.78 & 8.96 & 10.78 & 8.96 & 10.09 \\
Frame 8 & 9.63 & 8.95 & 8.43 & 7.75 & 8.67 \\
\hline
\end{tabular}

$9.80 \mathrm{~W} / \mathrm{m}^{2} \mathrm{~K}$ is frame $5\left(9.88 \mathrm{~W} / \mathrm{m}^{2} \mathrm{~K}\right)$. A relative difference of $21 \%$ is calculated between the extreme values, while the standard deviation associated with the eight values is $0.64 \mathrm{~W} / \mathrm{m}^{2} \mathrm{~K}$ ( $6.5 \%$ of the average value).

The results are not consistent with the performance level claimed by manufacturers, used as classification criteria in Section 3.1. Indeed, frames 1 and 2 both belong to economy lines, whereas frames 6 and 8 are considered to be top-of-the-line products according to the manufacturers. Those performance levels can be linked to the sash width. Therefore, it appears that the performance level indicated by the manufacturers is not related to thermal performance, but rather to frame sturdiness.
Edge effects at the interface between the frame and the glazing are considered and calculated. However, since relative impact values are negligible ( $-1 \%)$, edge effects will not be considered hereafter.

EnergyPlus Reports were created in WINDOW for every case study, showing that all samples have the same conductance value of $500 \mathrm{~W} / \mathrm{m}^{2} \mathrm{~K}$. Since a relative difference of $21 \%$ was found for the U-factors between frames 1 and 2 under the same environmental conditions, this result reveals that the method employed to calculate the frame conductance has shortcomings.

\subsection{Analysis of the traditional frame conductance model}

The model used by WINDOW to calculate the frame conductance is based on Equation (1), in which thermal transmittance is expressed as a function of conductance and inside and outside film coefficients. One simulation is required to know $U_{\mathrm{f}}$ and then deduce $K_{\mathrm{f}}$. This value is supposed to be a constant (independent of film coefficient variations) and is used by simulation software to estimate heat transfer through window frames at each time step.

$$
\frac{1}{U_{\mathrm{f}}}=\frac{1}{K_{\mathrm{f}}}+\frac{1}{h_{\mathrm{i}}}+\frac{1}{h_{\mathrm{o}}}
$$

The coefficients $h_{\mathrm{i}}$ and $h_{\mathrm{o}}$ which appear in model (1) are combined film coefficients, which describe the convective and radiative exchanges at the inside and outside surfaces of the frame. However, the NFRC procedure advocates the use of detailed radiation models, which, as previously mentioned, improves the accuracy of simulated U-factors for projecting windows, especially for lower performance products (Griffith et al. 1998). The detailed radiation model uses view factors to calculate the radiative transfer between surfaces with different temperatures depending on the emissivity of each part of the surface. Since the outer and inner surfaces are not isothermal (as can be seen in Figure 3 where the temperatures of section S1 of frame 1 are displayed), this model results in non-uniform radiative coefficients, which depend on the window and surrounding geometry as well as superficial 
Table 4. Frame, edge-of-glass, centre-of-glass and window $U$-factors $\left(\mathrm{W} / \mathrm{m}^{2} \mathrm{~K}\right)$ for the eight study cases.

\begin{tabular}{lrcccccc}
\hline & \multicolumn{1}{c}{$U_{\mathrm{f}}$} & $U_{\mathrm{e}}$ & $U_{\mathrm{cog}}$ & $U_{\mathrm{w}}$ & $K_{\mathrm{f}}$ & $\Delta=\left(U_{\mathrm{e}}-U_{\mathrm{cog}}\right)^{*} A_{\mathrm{e}} / A_{\mathrm{w}}$ & $\Delta / U_{\mathrm{w}}$ \\
\hline Frame 1 & 10.62 & 5.65 & 5.85 & 7.05 & 500 & -0.04 & -0.01 \\
Frame 2 & 8.81 & 5.68 & 5.85 & 6.48 & 500 & -0.04 & -0.01 \\
Frame 3 & 10.10 & 5.57 & 5.77 & 7.00 & 500 & -0.04 & -0.01 \\
Frame 4 & 9.93 & 5.63 & 5.85 & 6.94 & 500 & -0.01 \\
Frame 5 & 9.88 & 5.55 & 5.77 & 7.05 & 500 & -0.07 & -0.01 \\
Frame 6 & 10.38 & 5.42 & 5.77 & 7.21 & 500 & -0.05 & -0.01 \\
Frame 7 & 9.90 & 5.51 & 5.77 & 7.32 & 500 & & -0.01 \\
Frame 8 & 8.79 & 5.36 & 5.74 & 6.84 & 500 & & -0.01 \\
Average & 9.80 & & & & & & \\
\hline
\end{tabular}

Note: Absolute and relative impact of edge effects consideration.

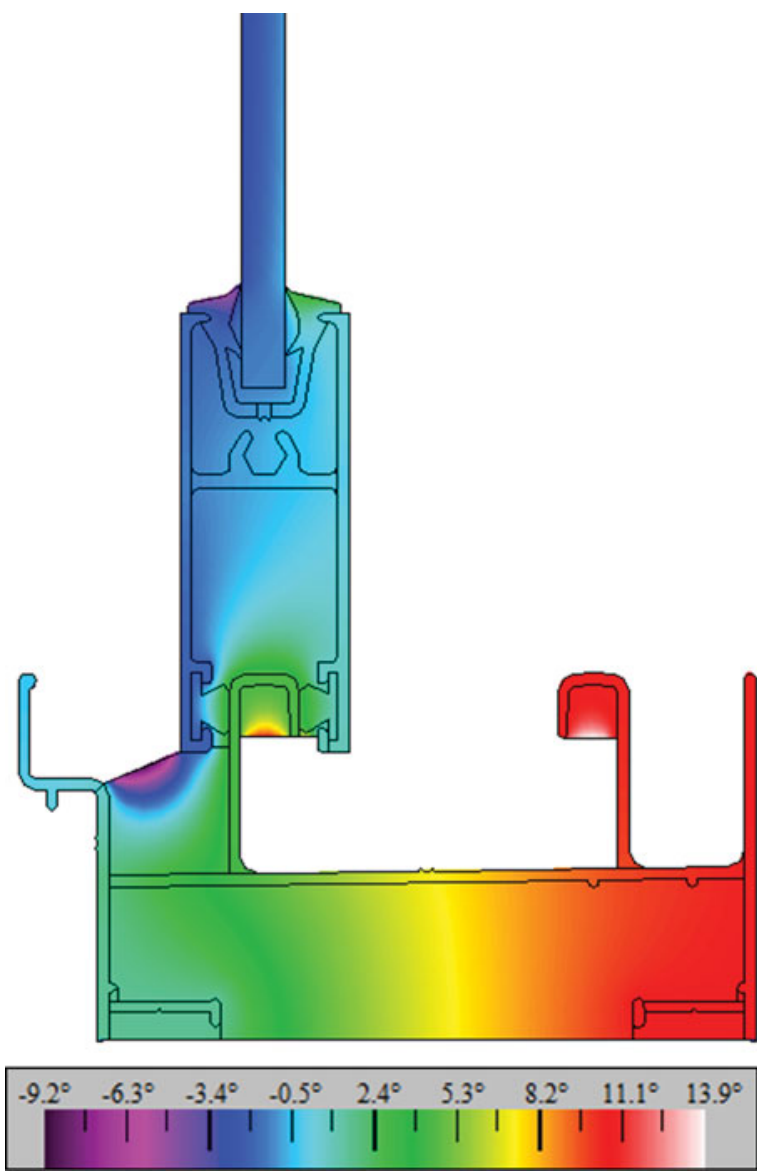

Figure 3. Temperature distribution $\left({ }^{\circ} \mathrm{C}\right)$ in $\mathrm{S} 1$ of frame 1.

temperatures. Therefore, the local values of $h_{\mathrm{i}}$ and $h_{\mathrm{o}}$ considered in THERM simulations are unknown. In order to apply model (1), it is supposed that there exist equivalent combined film coefficients - constant on the whole boundary surfaces - which produce the same global heat transfer as if detailed radiation models were used (as stated in NFRC procedures).

The combined film coefficients considered by WINDOW to be equivalent to NFRC boundary conditions are $h_{\mathrm{i}}=8 \mathrm{~W} / \mathrm{m}^{2} \mathrm{~K}$ and $h_{\mathrm{o}}=30 \mathrm{~W} / \mathrm{m}^{2} \mathrm{~K}$. Nevertheless, replacing the terms in Equation (1) by those values and the sample U-factors calculated in Section 3.2.2 leads to negative conductance values. In response to this situation, the program yields the default result of $K_{\mathrm{f}}=500 \mathrm{~W} / \mathrm{m}^{2} \mathrm{~K}$. This means that all frames with a U-factor higher than $6.2 \mathrm{~W} / \mathrm{m}^{2} \mathrm{~K}$ will be considered the same way when running a simulation in a building energy simulation program, whereas the frames studied in this work produce $40-70 \%$ more heat loss than a frame with a U-factor of $6.2 \mathrm{~W} / \mathrm{m}^{2} \mathrm{~K}$.

A cause for this shortcoming could be the use of the wrong equivalent combined film coefficient. Indeed, simulating section $\mathrm{S} 1$ of frame 1 with $h_{\mathrm{i}}=8 \mathrm{~W} / \mathrm{m}^{2} \mathrm{~K}$ and $h_{\mathrm{o}}=$ $30 \mathrm{~W} / \mathrm{m}^{2} \mathrm{~K}$ results in a U-factor of $U_{S_{1}}=13.89 \mathrm{~W} / \mathrm{m}^{2} \mathrm{~K}$, which is $26 \%$ higher than the value of $11.06 \mathrm{~W} / \mathrm{m}^{2} \mathrm{~K}$ calculated in Section 3.2.1 using detailed radiation models. The correct combined film coefficients were determined for this section by trying successively different coefficients for the inside and then for the outside boundaries, until the simulation resulted in the same $\mathrm{U}$-factor $\left(U_{S_{1}}=11.06 \mathrm{~W} / \mathrm{m}^{2} \mathrm{~K}\right)$. The film coefficients found in this case to be equivalent to NFRC boundary conditions are $h i_{\mathrm{eq}}=5.62 \mathrm{~W} / \mathrm{m}^{2} \mathrm{~K}$ and $h o_{\text {eq }}=29.58 \mathrm{~W} / \mathrm{m}^{2} \mathrm{~K}$. Those values verify $\frac{1}{h_{\mathrm{ieq}}}+\frac{1}{h_{\mathrm{eeq}}}>$ $\frac{1}{U_{1}}$, which invalidates model (1) for this section.

The reasons that could explain why Equation (1) does not apply to the frames studied in this work are the following: First, the frames are not homogeneous materials, but have many internal cavities that result in a threedimensional heat flux (modelled as a two-dimensional flux when neglecting edge effect around the frame corners). This is illustrated in Figure 4 which displays the heat flux magnitude through section S1 of frame 1. Second, the inside and outside surfaces of the frames are not flat, but highly non-planar (as seen in Section 3.1), which means that heat transfer is increased in comparison to that of a frame with a flat surface.

Sections S1 and S2 of frames 2, 4 and 6 are symmetrical. Therefore, their conductance values should be equal. According to model (1), this would mean that their U-factors are equal too. However, it was observed that section S1 (with external leaf) U-factors for those frames are, respectively, $29 \%, 16 \%$ and $14 \%$ higher than section 


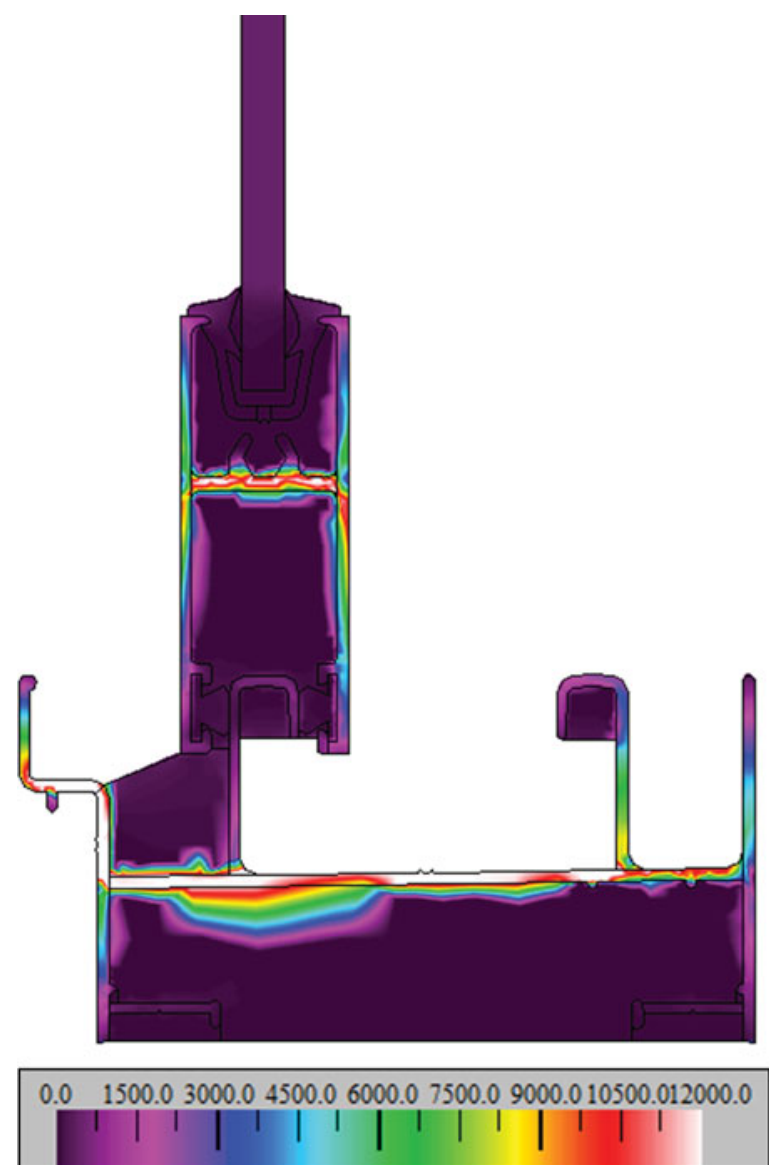

Figure 4. Flux magnitude $\left(\mathrm{W} / \mathrm{m}^{2}\right)$ through section $\mathrm{S} 1$ of frame 1.

S2 (with internal leaf) U-factors. This implies that an alternative model should be able to differentiate sections with internal and external leaf.

The above leads to the hypothesis that the ratios between the surface areas exposed to inside and outside film coefficients and the projected boundary surface area play a key role in U-factor. If true, this assumption would explain why jamb sections with a more compact morphology have lower U-factors, as seen in Section 3.2.1. It would also justify why frame 2 has a significantly lower U-factor than frame 1, despite being very similar in shape and dimensions, since it has no lateral fin, which means that less surface is exposed to environmental conditions.

\subsection{Development of an alternative model $U_{\mathrm{f}}\left(\boldsymbol{h}_{\mathrm{i}}, \boldsymbol{h}_{\mathrm{o}}\right)$}

\subsubsection{Model $U_{S_{j}}\left(h_{i} ; h_{\mathrm{o}}\right)$ for one section of the frame}

As anticipated in the methodology section, this study focuses first on a single section, for simplification. In order to determine which section has the greatest influence on the whole frame U-factor, the product of the projected area by the U-factor was calculated for each section. Figure 5 shows the respective weights of each section on the total frame U-factor for the eight case studies. It evidences that in all case studies, the sill with external sash is the most relevant section, followed by the sill section with internal sash, which has the same projected area but lower thermal transmittance, as observed previously. That is the reason why the following analysis is based on the study of section S1 of the eight case studies.

Parameters $\mathrm{L}_{i}$ and $\mathrm{L}_{\mathrm{o}}$ are defined, as shown in Figure 6, as the lengths of the inside and outside profile boundaries, considering the slightly ventilated cavities. The projected height is designated as $\mathrm{H}$.

Equation (2) is proposed as an alternative model. The film coefficients are weighted by the inside and outside compactness factors $\mathrm{x}_{\mathrm{i}}$ and $\mathrm{x}_{0}$ in order to take into account the ratio between the surfaces exposed to boundary conditions and the projected area.

$$
\begin{gathered}
\frac{1}{U_{S_{j}}}=\frac{1}{K_{S_{j}}}+\frac{x_{\mathrm{i}_{s_{j}}}}{h_{\mathrm{i}}}+\frac{x_{\mathrm{o}_{S_{j}}}}{h_{\mathrm{o}}} ; \\
x_{\mathrm{i}_{s_{j}}}=\frac{H_{S_{j}}}{L_{\mathrm{i}_{S_{j}}}} ; \quad x_{\mathrm{o}_{S_{j}}}=\frac{H_{S_{j}}}{L_{\mathrm{o}_{S_{j}}}} .
\end{gathered}
$$

To check the validity of the proposed model $U_{S_{j}}\left(h_{\mathrm{i}} ; h_{\mathrm{o}}\right)$, six combinations of inside and outside film coefficients $\left(h_{\mathrm{i}} ; h_{\mathrm{o}}\right)$ are defined and the eight $\mathrm{S} 1$ sections are simulated under these conditions. Also, the $U_{S_{1}}$ values are

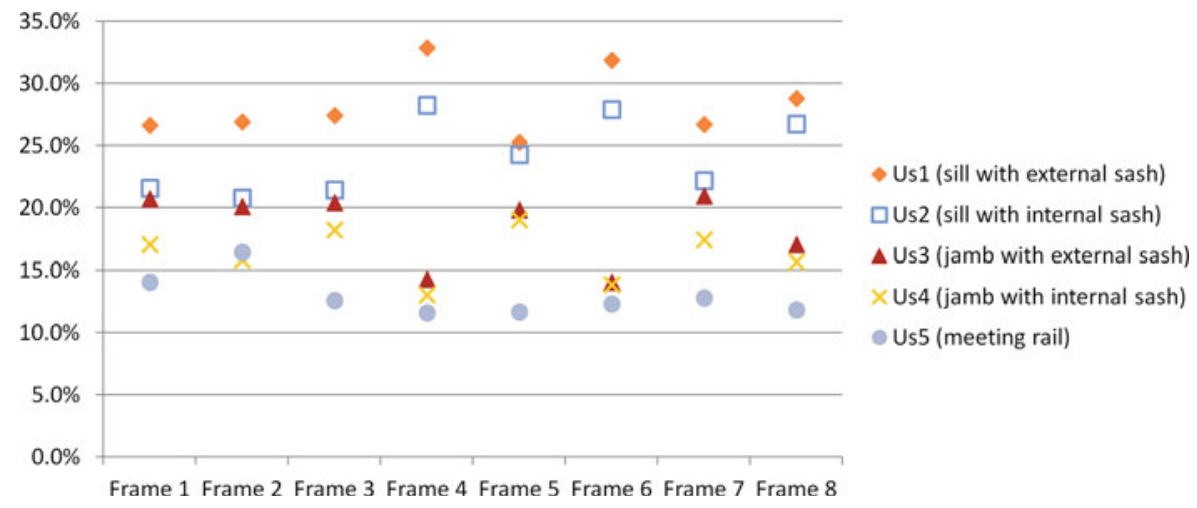

Figure 5. Proportion of the total frame heat transfer by section (standard window dimensions $1200 \mathrm{~mm} \times 1500 \mathrm{~mm}$ ). 


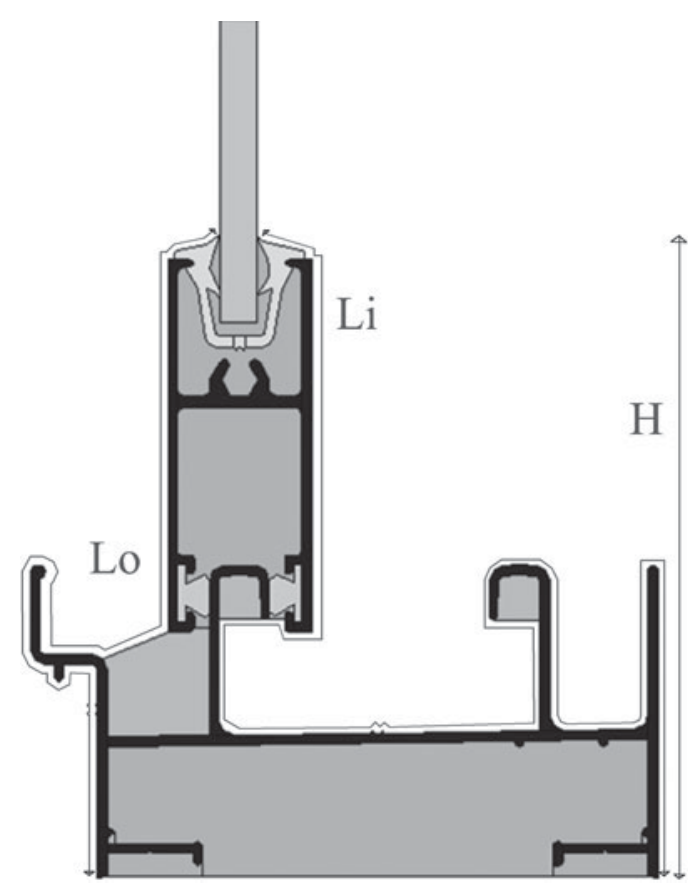

Figure 6. Definition of the characteristic lengths of the frame section: $L_{\mathrm{i}}, L_{\mathrm{o}}$ and $H$.

estimated using model (2), which requires one initial simulation (realized with $h_{\mathrm{i}}=8 \mathrm{~W} / \mathrm{m}^{2} \mathrm{~K}$ and $h_{\mathrm{o}}=30 \mathrm{~W} / \mathrm{m}^{2} \mathrm{~K}$ ). From the simulated values $U_{S_{1}}(8 ; 30)$ and every profile characteristic morphology parameters $\left(L_{\mathrm{i}}, L_{\mathrm{o}}\right.$ and $\left.H\right)$, the conductance values $K_{S_{1}}$ are calculated. Then, section S1 U-factors are deduced from Equation (2) for the rest of the boundary conditions.

Table 5 shows the measured values of the lengths $L_{\mathrm{i}}, L_{\mathrm{o}}$ and $H$; the corresponding values for the compactness factors and finally the calculated conductance values. Table 6 compares the U-factors calculated according to model (2) with the simulated U-factors, and exhibits the corresponding RMSE for each of the eight sections. It is verified that the resulting conductance values are positive. They vary between 66.8 and $223.8 \mathrm{~W} / \mathrm{m}^{2} \mathrm{~K}$. Those differences are assumed to come from the internal geometry of the frames, but no obvious relationship between the conductance values and the geometry of the frames could be found.
The maximum RMSE is $0.12 \mathrm{~W} / \mathrm{m}^{2} \mathrm{~K}$ (section $\mathrm{S} 1$ of frame 2). The maximum relative difference $(2.4 \%)$ corresponds to the value $U_{S_{1}}(6 ; 12)$ for frame 2 . Therefore, it can be concluded that the model fits well, and that the hypothesis formulated in Section 3.3 - strong dependence of non-planar thermally unbroken aluminium frame U-factor to the ratio between the surface area exposed to environmental conditions and the projected area - is verified for one section.

\subsubsection{Model $U_{\mathrm{f}}\left(h_{\mathrm{i}} ; h_{\mathrm{o}}\right)$ for the whole frame}

Once the validity of the model proposed for one section was verified, a model for the entire frame was sought. Although Equation (2) is not linear, an attempt was made to extrapolate it through Equation (3), where the factors $H / L_{\mathrm{i}}$ and $H / L_{\mathrm{o}}$ of every section are area-weighted to get the compactness factors $X_{\mathrm{i}}$ and $X_{\mathrm{o}}$ for the whole frame. This weighting is needed because of the important variability of compactness that may exist between the different sections of the frame.

$$
\begin{aligned}
\frac{1}{U_{\mathrm{f}}} & =\frac{1}{K_{\mathrm{f}}}+\frac{X_{\mathrm{i}}}{h_{\mathrm{i}}}+\frac{X_{\mathrm{o}}}{h_{\mathrm{o}}} ; \quad X_{\mathrm{i}}=\sum_{j} \frac{A_{S_{j}}}{A_{\mathrm{f}}} \cdot \frac{H_{S_{j}}}{L_{\mathrm{i}_{S_{j}}}} ; \\
X_{\mathrm{o}} & =\sum_{j} \frac{A_{S_{j}}}{A_{\mathrm{f}}} \cdot \frac{H_{S_{j}}}{L_{\mathrm{o}_{S_{j}}}} .
\end{aligned}
$$

The method used to evaluate the model predictions with respect to the simulated values is the same as in Section 3.4.1. On the one hand, each frame is simulated using the film coefficients 8 and $30 \mathrm{~W} / \mathrm{m}^{2} \mathrm{~K}$; then, its conductance value $K_{\mathrm{f}}$ is calculated from the result $U_{\mathrm{f}}$ $(8 ; 30)$ along with the calculation of the compactness factors $X_{\mathrm{i}}$ and $X_{\mathrm{o}}$ (see Table 7). Finally, the frame U-factors under the rest of the boundary conditions are estimated using Equation (3). On the other hand, the frames are simulated under the same sets of boundary conditions in WINDOW and THERM. Then, the values obtained through both procedures are compared. Since this method is time-consuming, three frames were selected within the case studies: frame 1 (highest U-factor), frame 2 (lowest U-factor) and frame 5 (closest to average U-factor). Table 8 compares the results obtained by simulation and

Table 5. Measured values: $L_{\mathrm{i}}, L_{\mathrm{o}}$ and $H$, and calculated values: $X_{\mathrm{i}}, X_{\mathrm{o}}$ and $K_{S_{1}}$.

\begin{tabular}{lcccccc}
\hline & $L_{\mathrm{i}}(\mathrm{mm})$ & $L_{\mathrm{o}}(\mathrm{mm})$ & $h(\mathrm{~mm})$ & $h / L_{\mathrm{i}}$ & $h / L_{\mathrm{o}}$ & $K_{S_{1}}\left(\mathrm{~W} / \mathrm{m}^{2} \mathrm{~K}\right)$ \\
\hline S1 of Frame 1 & 260 & 143 & 86 & 0.331 & 0.601 & 99.6 \\
S1 of Frame 2 & 195 & 84 & 73 & 0.374 & 0.869 & 66.8 \\
S1 of Frame 3 & 255 & 194 & 93 & 0.365 & 0.479 & 147.4 \\
S1 of Frame 4 & 280 & 198 & 97 & 0.346 & 0.490 & 223.8 \\
S1 of Frame 5 & 274 & 135 & 103 & 0.376 & 0.763 & 142.7 \\
S1 of Frame 6 & 364 & 252 & 110 & 0.302 & 0.437 & 138.2 \\
S1 of Frame 7 & 318 & 272 & 125 & 0.393 & 0.460 & 194.7 \\
S1 of Frame 8 & 350 & 174 & 131 & 0.374 & 0.753 & 102.6 \\
\hline
\end{tabular}


Table 6. Comparison in $\mathrm{W} / \mathrm{m}^{2} \mathrm{~K}$ of the values of $U_{S_{1}}\left(h_{\mathrm{i}} ; h_{\mathrm{o}}\right)$ obtained from simulation and the calculated values according to Equation (2).

\begin{tabular}{|c|c|c|c|c|c|c|c|c|}
\hline & & $(6 ; 12)$ & $(8 ; 12)$ & $(8,16)$ & $(8 ; 24)$ & $(8 ; 30)$ & $(10 ; 30)$ & RMSE \\
\hline Frame 1 & $\begin{array}{l}1 / U_{S_{1}}=1 / K+0.331 / h_{\mathrm{i}}+0.601 / h_{\mathrm{o}} \\
\text { Simulation }\end{array}$ & $\begin{array}{l}8.63 \\
8.62\end{array}$ & $\begin{array}{l}9.80 \\
9.81\end{array}$ & $\begin{array}{l}11.17 \\
11.16\end{array}$ & $\begin{array}{l}12.99 \\
12.98\end{array}$ & $\begin{array}{l}13.89 \\
13.89\end{array}$ & $\begin{array}{l}15.69 \\
15.74\end{array}$ & 0.02 \\
\hline Frame 2 & $\begin{array}{l}1 / U_{S_{1}}=1 / K+0.384 / h_{\mathrm{i}}+0.869 / h_{\mathrm{o}} \\
\text { Simulation }\end{array}$ & $\begin{array}{l}6.65 \\
6.49\end{array}$ & $\begin{array}{l}7.42 \\
7.29\end{array}$ & $\begin{array}{l}8.57 \\
8.43\end{array}$ & $\begin{array}{l}10.14 \\
10.05\end{array}$ & $\begin{array}{l}10.94 \\
10.94\end{array}$ & $\begin{array}{l}12.19 \\
12.32\end{array}$ & 0.12 \\
\hline Frame 3 & $\begin{array}{l}1 / U_{S_{1}}=1 / K+0.365 / h_{\mathrm{i}}+0.479 / h_{\mathrm{o}} \\
\text { Simulation }\end{array}$ & $\begin{array}{l}9.30 \\
9.26\end{array}$ & $\begin{array}{l}10.83 \\
10.81\end{array}$ & $\begin{array}{l}12.15 \\
12.13\end{array}$ & $\begin{array}{l}13.82 \\
13.81\end{array}$ & $\begin{array}{l}14.63 \\
14.63\end{array}$ & $\begin{array}{l}16.88 \\
16.95\end{array}$ & 0.03 \\
\hline Frame 4 & $\begin{array}{l}1 / U_{S_{1}}=1 / K+0.346 / h_{\mathrm{i}}+0.490 / h_{\mathrm{o}} \\
\text { Simulation }\end{array}$ & $\begin{array}{l}9.71 \\
9.76\end{array}$ & $\begin{array}{l}11.29 \\
11.34\end{array}$ & $\begin{array}{l}12.76 \\
12.79\end{array}$ & $\begin{array}{l}14.67 \\
14.64\end{array}$ & $\begin{array}{l}15.60 \\
15.60\end{array}$ & $\begin{array}{l}18.03 \\
18.02\end{array}$ & 0.04 \\
\hline Frame 5 & $\begin{array}{l}1 / U_{s_{1}}=1 / K+0.376 / h_{\mathrm{i}}+0.763 / h_{\mathrm{o}} \\
\text { Simulation }\end{array}$ & $\begin{array}{l}7.51 \\
7.50\end{array}$ & $\begin{array}{l}8.51 \\
8.51\end{array}$ & $\begin{array}{l}9.83 \\
9.82\end{array}$ & $\begin{array}{l}11.66 \\
11.64\end{array}$ & $\begin{array}{l}12.59 \\
12.59\end{array}$ & $\begin{array}{l}14.28 \\
14.30\end{array}$ & 0.01 \\
\hline Frame 6 & $\begin{array}{l}1 / U_{S_{1}}=1 / K+0.302 / h_{\mathrm{i}}+0.437 / h_{\mathrm{o}} \\
\text { Simulation }\end{array}$ & $\begin{array}{l}10.64 \\
10.63\end{array}$ & $\begin{array}{l}12.28 \\
12.29\end{array}$ & $\begin{array}{l}13.83 \\
13.83\end{array}$ & $\begin{array}{l}15.82 \\
15.82\end{array}$ & $\begin{array}{l}16.79 \\
16.79\end{array}$ & $\begin{array}{l}19.23 \\
19.27\end{array}$ & 0.02 \\
\hline Frame 7 & $\begin{array}{l}1 / U_{s_{1}}=1 / K+0.393 / h_{\mathrm{i}}+0.460 / h_{\mathrm{o}} \\
\text { Simulation }\end{array}$ & $\begin{array}{l}9.18 \\
9.20\end{array}$ & $\begin{array}{l}10.80 \\
10.81\end{array}$ & $\begin{array}{l}12.05 \\
12.05\end{array}$ & $\begin{array}{l}13.62 \\
13.62\end{array}$ & $\begin{array}{l}14.37 \\
14.37\end{array}$ & $\begin{array}{l}16.73 \\
16.71\end{array}$ & 0.01 \\
\hline Frame 8 & $\begin{array}{l}1 / U_{S_{1}}=1 / K+0.374 / h_{\mathrm{i}}+0.753 / h_{\mathrm{o}} \\
\text { Simulation }\end{array}$ & $\begin{array}{l}7.41 \\
7.30\end{array}$ & $\begin{array}{l}8.38 \\
8.27\end{array}$ & $\begin{array}{l}9.65 \\
9.54\end{array}$ & $\begin{array}{l}11.38 \\
11.31\end{array}$ & $\begin{array}{l}12.25 \\
12.25\end{array}$ & $\begin{array}{l}13.83 \\
13.87\end{array}$ & 0.09 \\
\hline
\end{tabular}

Table 7. Compactness factors $X_{\mathrm{i}}$ and $X_{\mathrm{o}}$ for the eight case studies.

\begin{tabular}{lcc}
\hline & $X_{\mathrm{i}}$ & $X_{\mathrm{o}}$ \\
\hline Frame 1 & 0.575 & 0.432 \\
Frame 2 & 0.563 & 0.563 \\
Frame 3 & 0.584 & 0.459 \\
Frame 4 & 0.545 & 0.545 \\
Frame 5 & 0.604 & 0.560 \\
Frame 6 & 0.478 & 0.478 \\
Frame 7 & 0.481 & 0.418 \\
Frame 8 & 0.628 & 0.624 \\
\hline
\end{tabular}

by applying model (3). The relative difference between both methods is indicated, as well as the RMSE for the six film coefficient combinations. The RMSE values obtained in the three case studies are, respectively, 0.29-0.26$0.18 \mathrm{~W} / \mathrm{m}^{2} \mathrm{~K}$. Relative differences under $5.5 \%$ are obtained, which is considered to be in good agreement since the simulation software - THERM - has a typical error of $10 \%$. Table 9 compares the results obtained from simulation and from model (1), where the default value of $500 \mathrm{~W} / \mathrm{m}^{2} \mathrm{~K}$ was used for the conductance. The RMSE values obtained are, respectively, 4.68-3.40-3.66 W/ $\mathrm{m}^{2} \mathrm{~K}$. Relative differences between -36 and $-47 \%$ are observed. This illustrates the importance of proposing a new model for describing aluminium frame U-factor variations.

\subsubsection{Application of the model to a thermally broken aluminium frame}

In order to determine whether the proposed model applies to other frame technologies, a thermally broken aluminium slider window frame was simulated in THERM under the same six inside and outside film coefficient combinations. Figure 7 shows the sill/jamb and meeting rail sections for the selected frame. It can be observed that its morphology is also non-planar and highly inhomogeneous. The Ufactor of this frame was found to be $4.97 \mathrm{~W} / \mathrm{m}^{2} \mathrm{~K}$ in accordance with the NFRC procedure. Although it has double glazing with a metallic spacer, the edge effects are reduced $\left(\Delta / U_{\mathrm{w}}=2 \%\right)$. Table 10 displays the simulation results as well as the values obtained from traditional conductance calculation model (1) and from proposed alternative model (3). The RMSE is calculated for both models.

Both models show good agreement with the simulation results. The RMSE for model (1) is slightly higher than that for model (3), but remains under $6 \%$ of the frame Ufactor. Again, considering that the simulation software has a typical error of $10 \%$, it can be concluded that both models are adequate for this frame technology.

\section{Discussion}

As mentioned in Section 1, there is little information about typical thermal transmittance values for thermally unbroken aluminium frame and the reliability of the available information is uncertain. As a result of the morphological study carried out in Section 3.1, eight thermally unbroken aluminium slider window frames representative of the Argentinean market were selected. Their U-factors, calculated according to NFRC, vary between 8.79 and $10.62 \mathrm{~W} / \mathrm{m}^{2} \mathrm{~K}$ with an average value of $9.80 \mathrm{~W} / \mathrm{m}^{2} \mathrm{~K}$. Those results confirm that the values published by ASHRAE are outdated (by 37\% error). The reference values provided by the Argentinean norm are not acceptable either (by $-39 \%$ error). It was detected that aluminium slider window frames in Argentina are 
Table 8. Comparison in $\mathrm{W} / \mathrm{m}^{2} \mathrm{~K}$ between results obtained from simulation and from model (3).

\begin{tabular}{llllllll}
\hline & $(6 ; 12)$ & $(8 ; 12)$ & $(8,16)$ & $(8 ; 24)$ & $(8 ; 30)$ & $(10 ; 30)$ & RMSE \\
\hline Frame 1 & & & & & & & \\
Uf1 from simulation & 7.39 & 8.73 & 9.64 & 10.81 & 11.42 & 13.25 & 0.29 \\
Uf1 from Equation (3) & 7.53 & 9.17 & 9.99 & 10.97 & 11.42 & 13.65 & \\
Relative difference (\%) & $1.88 \%$ & $5.09 \%$ & $3.60 \%$ & $1.47 \%$ & $0.00 \%$ & $2.96 \%$ & \\
Frame 2 & & & & & & & \\
Uf2 from simulation & 6.39 & 7.47 & 8.34 & 9.52 & 10.13 & 11.73 & \\
Uf2 from Equation (3) & 6.65 & 7.88 & 8.69 & 9.67 & 10.13 & 11.82 & \\
Relative difference (\%) & $4.20 \%$ & $5.48 \%$ & $4.21 \%$ & $1.65 \%$ & $0.00 \%$ & $0.80 \%$ & \\
Frame 5 & & & & & & & \\
Uf5 from simulation & 6.57 & 7.77 & 8.62 & 9.76 & 10.35 & 12.04 & \\
Uf5 from Equation (3) & 6.68 & 8.02 & 8.85 & 9.87 & 10.35 & 12.27 & \\
Relative difference (\%) & $1.55 \%$ & $3.33 \%$ & $2.72 \%$ & $1.20 \%$ & $0.00 \%$ & $1.92 \%$ & \\
\hline
\end{tabular}

Table 9. Comparison in $\mathrm{W} / \mathrm{m}^{2} \mathrm{~K}$ between simulation and model (1) results (with default $K_{\mathrm{f}}=500 \mathrm{~W} / \mathrm{m}^{2} \mathrm{~K}$ ).

\begin{tabular}{|c|c|c|c|c|c|c|c|}
\hline & $(6 ; 12)$ & $(8 ; 12)$ & $(8,16)$ & $(8 ; 24)$ & $(8 ; 30)$ & $(10 ; 30)$ & RMSE \\
\hline \multicolumn{8}{|l|}{ Frame 1} \\
\hline Uf1 from simulation & 7.39 & 8.73 & 9.64 & 10.81 & 11.42 & 13.25 & \multirow[t]{3}{*}{4.68} \\
\hline Uf1 from Equation (1) & 3.97 & 4.75 & 5.28 & 5.93 & 6.24 & 7.39 & \\
\hline Relative difference $(\%)$ & $-46.28 \%$ & $-45.52 \%$ & $-45.27 \%$ & $-45.16 \%$ & $-45.38 \%$ & $-44.25 \%$ & \\
\hline \multicolumn{8}{|l|}{ Frame 2} \\
\hline Uf2 from simulation & 6.39 & 7.47 & 8.34 & 9.52 & 10.13 & 11.73 & \multirow{3}{*}{3.40} \\
\hline Uf2 from Equation (1) & 3.97 & 4.75 & 5.28 & 5.93 & 6.24 & 7.39 & \\
\hline Relative difference $(\%)$ & $-37.85 \%$ & $-36.40 \%$ & $-36.70 \%$ & $-37.70 \%$ & $-38.45 \%$ & $-36.99 \%$ & \\
\hline \multicolumn{8}{|l|}{ Frame 5} \\
\hline Uf5 from simulation & 6.57 & 7.77 & 8.62 & 9.76 & 10.35 & 12.04 & \multirow[t]{3}{*}{3.66} \\
\hline Uf5 from Equation (1) & 3.97 & 4.75 & 5.28 & 5.93 & 6.24 & 7.39 & \\
\hline Relative difference $(\%)$ & $-39.64 \%$ & $-38.78 \%$ & $-38.78 \%$ & $-39.23 \%$ & $-39.75 \%$ & $-38.63 \%$ & \\
\hline
\end{tabular}

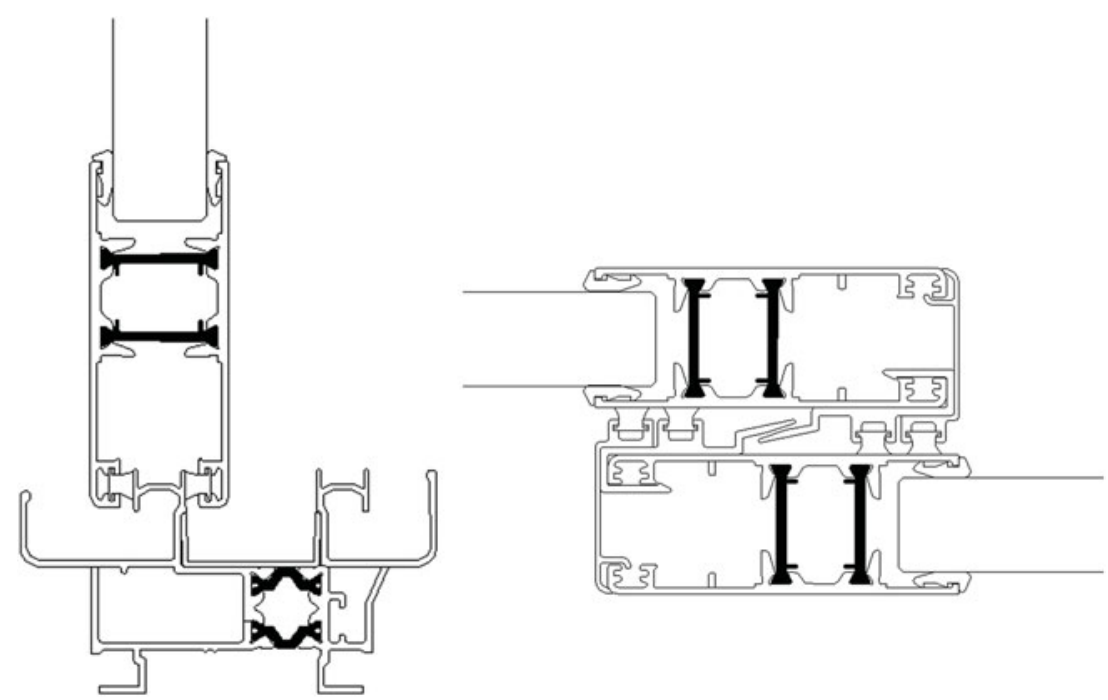

Figure 7. Thermally broken aluminium frame (Frame 9). Sill/jamb and meeting rail sections.

highly non-planar (the ratios of total to projected boundary surface area are comprised between 1.69 and 2.58) and have very heterogeneous thermal behaviours, within each section as well as between one section and another. In addition, it was observed that thermal performance is not linked to performance level announced by manufacturers (which depends on frame robustness), but is closely related to frame compactness. 
Table 10. Comparison in $\mathrm{W} / \mathrm{m}^{2} \mathrm{~K}$ between thermally broken frame results obtained from simulation and calculated from models (3) and (1).

\begin{tabular}{lccccccc}
\hline & $(6 ; 12)$ & $(8 ; 12)$ & $(8,16)$ & $(8 ; 24)$ & $(8 ; 30)$ & $(10 ; 30)$ & RMSE \\
\hline $\begin{array}{l}\text { Thermally broken frame } \\
\text { Uf9 from simulation }\end{array}$ & 4.19 & 4.78 & 5.08 & 5.46 & 5.64 & 6.29 & \\
Uf9 from Equation (3) & 4.44 & 5.01 & 5.26 & 5.53 & 5.64 & 6.18 & 0.17 \\
Relative difference (\%) & $5.97 \%$ & $5.00 \%$ & $3.49 \%$ & $1.20 \%$ & $0.00 \%$ & $-1.80 \%$ & \\
Uf9 from Equation (1) & 3.72 & 4.40 & 4.84 & 5.39 & 5.64 & 6.57 & 0.29 \\
Relative difference (\%) & $-11.31 \%$ & $-7.85 \%$ & $-4.65 \%$ & $-1.33 \%$ & $0.00 \%$ & $4.40 \%$ & \\
\hline
\end{tabular}

More specifically, for thermally unbroken aluminium frames, the inside and outside compactness factors were found to be the key parameters that govern the frame U-factor dependence on environmental conditions. They are obtained by area-weighting the ratios of projected to total boundary surface area of each frame section. However, even frames with better thermal performance are subject to differences in projected and actual exposed surface areas. This leads to a questioning of the traditional one-dimensional conductance model in general. The traditional one-dimensional conductance model - model (1) - could not properly describe the thermal behaviour of aluminium frames without thermal break. An alternative model - model (3) - was proposed to better estimate the frame U-factor variations depending on environmental conditions. By contrast, the U-factor variations for the thermally broken frame were sufficiently described by both models (1) and (3). This result is consistent with the affirmation that frame heat loss in most fenestration is controlled by a single controlling resistance (ASHRAE 2009). The thermal transmittance of aluminium frames without thermal break is governed by film coefficients; thus, the area exposed to environmental conditions is a relevant parameter. For frames built from other materials (thermally broken aluminium, vinyl and wood), the thermal transmittance essentially depends on one constant parameter (thermal break dimensions, distance between the inside and outside surfaces); thus, it is less subject to variations in response to fluctuations in environmental conditions.

In terms of equations, in both models (1) and (3), it can be observed that for given film coefficients, the lower the $U_{\mathrm{f}}$, the higher the $1 / K_{\mathrm{f}}$. This implies that for a better thermal performance of the frame, there should be less dependence on inside and outside air resistances. Therefore, since the traditional conductance model was found to be plausible for the example of aluminium thermally broken frame (Section 3.4.3), it can be assumed to be valid for all frames with a lower thermal transmittance $\left(U_{\mathrm{f}}<5 \mathrm{~W} / \mathrm{m}^{2} \mathrm{~K}\right)$. However, it is not suitable for frames with a U-factor higher than $6.2 \mathrm{~W} / \mathrm{m}^{2} \mathrm{~K}$ since (as discussed in Section 3.3) it leads to negative conductance values and thus requires the use of default conductance values, which implies significant errors in heat transfer estimates.

The proposed alternative conductance model was determined on the basis of simulations in THERM. In order to control the film coefficient inputs, a simplified radiation model was used (fixed coefficients over the entire boundary surfaces) even though the literature recommends the use of detailed radiation models. Hence, for the proposed model to give good results, it is necessary to determine the combined coefficients which, applied uniformly over the inside and outside boundary surfaces of the frame, result in the same global heat transfer as using local film coefficients (in accordance with the detailed radiation model and real environmental conditions). This means that new correlations are needed for $h_{i}$ and $h_{o}$ that take into account the frame morphology, including for frames under $5 \mathrm{~W} / \mathrm{m}^{2} \mathrm{~K}$ (since the traditional conductance model also requires the determination of combined film coefficients).

Thermal bridges at the interface between glass and frame were neglected in this work, but may become much more relevant in the case of high-performance windows. Installation thermal bridges were not considered either, in view of the fact that they can be computed within the wall transmittance. Nevertheless, since the determination of edge-of-glass and installation thermal bridges requires the use of two-dimensional calculation software like THERM, it would be useful to adapt these conductance models in order to incorporate thermal bridges into the frame conductance value. Future work should analyse the dependence of thermal bridges on environmental conditions, in order to determine whether thermal bridges should be taken into account through U-value (as proposed by Cappelletti et al. (2011)) or in an independent way.

Building energy simulation software should include the frame compactness factors introduced in this paper (or similar parameters) in order to take into account the frame morphology. Additional frame descriptors may also be necessary to fully reflect the 2D nature of frames, like, for example, relevant parameters for the estimation of radiation falling on the frame and shading on glass due to the frame. Additional research is needed to analyse these aspects. 


\section{Conclusion}

This paper demonstrates that the model used in most building simulation programs to calculate heat transfer through the frame at each iteration is not suitable for highly nonplanar and conductive windows. This is because the frame geometry is modelled as a rectangular section even though the frame U-factor variations due to environmental fluctuations are found to be a function of the ratio between the surface exposed to boundary conditions and the projected frame area. All in all, the traditional conductance model seems to be reliable for frames with a U-factor under $5 \mathrm{~W} / \mathrm{m}^{2} \mathrm{~K}$. In other words, the frame conductance model is acceptable for vinyl, wood and aluminium thermally broken frames, but not for aluminium frames without thermal break. This highlights the importance of looking into the models used by simulation programs to make sure they fit with the specific technology and climatic conditions.

An alternative model is proposed in order to more closely estimate thermal transmittance of the frame under any environmental condition with one single simulation. This alternative model expresses the frame U-factor as a function of inside and outside film coefficients, as well as characteristic dimensions of the frame. The model summarizes in a simple equation the simulation results from THERM, a two-dimensional software that takes into account the specific geometry of the frame. The proposed model shows good agreement with the results obtained from THERM (relative differences under 5.5\%). For the correct use of the proposed model, future works should examine how the non-planar frame morphology influences the radiative and convective exchanges, in order to establish new correlations for $h_{c}$ at the inside and outside surfaces of the frame, depending on its morphology.

\section{Nomenclature \\ A Area $\left(\mathrm{m}^{2}\right)$ \\ $H \quad$ Frame section height (mm) \\ $K \quad$ Thermal conductance $\left(\mathrm{W} / \mathrm{m}^{2} \mathrm{~K}\right)$ \\ $L \quad$ Frame section boundary length $(\mathrm{mm})$ \\ $R \quad$ Thermal resistance $\left(\mathrm{m}^{2} \mathrm{~K} / \mathrm{W}\right)$ \\ $U$ Thermal transmittance $\left(\mathrm{W} / \mathrm{m}^{2} \mathrm{~K}\right)$ \\ $X \quad$ Frame compactness factor $(-)$ \\ $h \quad$ Film coefficient $\left(\mathrm{W} / \mathrm{m}^{2} \mathrm{~K}\right)$ \\ $x \quad$ Section compactness factor (-)}

\section{Subscripts}

$\begin{array}{ll}\text { i } & \text { inside } \\ \text { o } & \text { outside } \\ \mathrm{f} & \text { frame } \\ S_{j} & \text { Section } j \text { of the frame } \\ \text { aswf } & \text { aluminium slider window frame }\end{array}$

\section{Funding}

This work was supported by CONICET (National Scientific and Technical Research Council), ANPCyT (Agencia Nacional de Promoción Científica y Tecnológica) under Grant PICT 20132089 Prest. BID. and ENARGAS (Ente Nacional Regulador del Gas) under Grant PICTO ENARGAS 2009-0133.

\section{References}

ASHRAE. 2009. 2009 ASHRAE Handbook - Fundamentals. Atlanta, GA: ASHRAE.

Berggren, Björn, and Maria Wall. 2013. "Calculation of Thermal Bridges in (Nordic) Building Envelopes - Risk of Performance Failure due to Inconsistent Use of Methodology." Energy and Buildings 65 (October): 331-339.

Booten, Chuck, Neal Kruis, and Craig Christensen. 2012. Identifying and Resolving Issues in Energyplus and DOE-2 Window Heat Transfer Calculations. Denver: NREL, Vol. 303.

Byars, Nan, and Dariush Arasteh. 1992. "Design Options for Low-Conductivity Window Frames." Solar Energy Materials and Solar Cells 25 (1): 143-148.

Cappelletti, Francesca, Andrea Gasparella, Piercarlo Romagnoni, and Paolo Baggio. 2011. "Analysis of the Influence of Installation Thermal Bridges on Windows Performance: The Case of Clay Block Walls." Energy and Buildings 43 (6): 1435-1442.

De Gastines, M., A. Villalba, and A. Pattini. 2014. "Determinación Del Factor K de Ventanas. Utilización de Programas de Simulación de Precisión Para Evaluar El Impacto Del Diseño de Marcos Y de Las Condiciones Climáticas." Avances En Energías Renovables Y Medio Ambiente 18: 08.35-08.42.

Elmahdy, A. H. 2006. "Assessment of Spacer bar Design and Frame Material on the Thermal Performance of Windows." ASHRAE Transactions 112 (pt. 2): 1-14.

Griffith, Brent, Dragan Curcija, Daniel Turler, and Dariush K. Arasteh. 1998. "Improving Computer Simulations of Heat Transfer for Projecting Fenestration Products: Using Radiation View-Factor Models." ASHRAE TransactionsAmerican Society of Heating Refrigerating Airconditioning Engin 104 (1): 845-855.

Gustavsen, Arild. 2008. "State-of-the-Art Highly Insulating Window Frames-Research and Market Review." Lawrence Berkeley National Laboratory 4: 77-99.

Gustavsen, Arild, Dariush Arasteh, Bjørn Petter Jelle, Charlie Curcija, and Christian Kohler. 2008. "Developing LowConductance Window Frames: Capabilities and Limitations of Current Window Heat Transfer Design Tools - Stateof-the-Art Review." Journal of Building Physics 32 (2): 131-153.

Gustavsen, Arild, Sivert Uvsløkk, and Bjørn Petter Jelle. 2005. "Numerical and Experimental Studies of the Effect of Various Glazing Spacers on the Window U-Value and the Glazing Temperature." Nordic building physics symposium (NBPS), Iceland.

International Energy Agency. 2013. Technology Roadmap Energy Efficient Building Envelopes. Paris: International Energy Agency. https://www.iea.org/publications/ freepublications/publication/TechnologyRoadmapEnergy EfficientBuildingEnvelopes.pdf

IRAM 11507-4. 2001. "N 11507-4: Carpintería de Obra Y Fachadas Integrales Livianas: Ventanas Exteriores: Parte 4: Requisitos Complementarios: Aislación Térmica." Buenos Aires, Argentina

ISO. 2003a. "10077-2: Thermal Performance of Windows, Doors and Shutters - Calculation of Thermal Transmittance-Part 2: 
Numerical Method for Frames (ISO 10077-2: 2003).” CEN, Brussels, Belgium.

ISO. 2003b. "15099. 2003. Thermal Performance of Windows, Doors and Shading Devices - Detailed Calculations." International Organization for Standardization, Geneva, Switzerland.

Lam, T. C., Hua Ge, and Paul Fazio. 2014. "Study of Different Glazing Modelling Approaches in Assessing Energy Performance of Curtain Wall Systems Using EnergyPlus." In eSIM, Ottawa, Canada.

Lomas, K. J., H. Eppel, C. J. Martin, and D. P. Bloomfield. 1997. "Empirical Validation of Building Energy Simulation Programs." Energy and Buildings 26 (3): 253-275.

Loutzenhiser, P. G., H. Manz, C. Felsmann, P. A. Strachan, and G. M. Maxwell. 2007a. "An Empirical Validation of Modeling Solar Gain through a Glazing Unit with External and Internal Shading Screens." Applied Thermal Engineering 27 (2): 528-538.

Loutzenhiser, P. G., H. Manz, C. Felsmann, P. A. Strachan, Th Frank, and G. M. Maxwell. 2007b. "Empirical Validation of Models to Compute Solar Irradiance on Inclined Surfaces for Building Energy Simulation.” Solar Energy 81 (2): 254 267.

Loutzenhiser, Peter G., Heinrich Manz, Sven Moosberger, and Gregory M. Maxwell. 2009. "An Empirical Validation of Window Solar Gain Models and the Associated Interactions." International Journal of Thermal Sciences 48 (1): 85-95.
Lyons, Peter, Justin Wong, and Mahabir Bhandari. 2010. "A Comparison of Window Modelling Methods in EnergyPlus 4.0." Fourth National Conference of IBPSA-USA, New York, August 11-13. http://www.ibpsa.us/sites/default/files/ publications/SB10-DOC-TS04A-04-Lyons.pdf.

Manz, H., P. Loutzenhiser, Th Frank, P. A. Strachan, R. Bundi, and G. Maxwell. 2006. "Series of Experiments for Empirical Validation of Solar Gain Modeling in Building Energy Simulation Codes - Experimental Setup, Test Cell Characterization, Specifications and Uncertainty Analysis." Building and Environment 41 (12): 1784-1797.

National Fenestration Rating Council. 2004. NFRC 100 2004, Procedure for Determining Fenestration Product U-Factors. Greenbelt, MD: National Fenestration Rating Council.

RDH Building Engineering. 2014. International Window Standards. Vancouver: RDH Building Engineering.

Robin, M., C. Kohler, D. Curcija, L. Zhu, S. Vidanovic, S. Czarnecki, and D. Aratesh. 2011. "THERM 6.3/WINDOW 6.3 NFRC Simulation Manual." California, USA

Strachan, Paul, Katalin Svehla, Ingo Heusler, and Matthias Kersken. 2015. "Whole Model Empirical Validation on a Full-Scale Building." Journal of Building Performance Simulation: 1-20. http://www.tandfonline.com/doi/full/10.1080/ 19401493.2015.1064480

Uiuc, Lbnl. 2009. EnergyPlus Engineering Reference: The Reference to EnergyPlus Calculations. Washington, DC: US Department of Energy. 